\title{
71. DOS SAPRÓFITOS DE INTERÉS PARA LA FLORA DE ALBACETE
}

\author{
Pedro SÁNCHEZ GÓMEZ, Miguel Angel CARRIÓN, Santiago FERNÁNDEZ y Gemma LÓPEZ
}

Two interesting saprophytes of the Albacete Flora.

Palabras clave: Saprófito, flora vascular, Albacete (España).

Key words: Saprophyte, vascular flora, Albacete (Spain).

La sierra del Calar del Mundo (Albacete) se encuadra desde el punto de vista biogeográfico en el Subsector AlcaracinoCazorlense, Sector Subbético, Provincia Bética (Sánchez-Gómez et al., 1994). En este territorio, bajo un ombroclima húmedo, se establecen bosques mixtos de carácter relictual en los que conviven especies como Quercus pyrenaica, Quercus faginea, Ilex aquifolium, Taxus baccata, Acer granatense, Ulmus glabra, etc. Bajo éstos, se producen suelos con una importante acumulación de materia orgánica y un ambiente nemoral, que propician la presencia de diversos elementos de óptimo centroeuropeo o submediterráneo, entre ellos algunos saprófitos vasculares, como los dados a conocer, nuevos para la flora albacetense.

\section{Monotropa hypopitys L.}

ALBACETE: Calar del Mundo (Vianos), 1300 m, 30SWH4652. 21-05-98. SánchezGómez, P., Carrión Vilches M.A., Fernández Jiménez S. \& López Vélez, G. MGC 46816. Taxon de distribución holártica. En Flora Iberica (cf. Montserrat Martí, 1993: 539) está indicado en las provincias vecinas de Granada, Jaén y Valencia.

Neottia nidus-avis (L.) L. C. Richard ALBACETE: Calar del Mundo (Vianos), 1300 m, 30SWH4652. 21-05-98. Sánchez-
Gómez, P., Carrión Vilches M.A., Fernández Jiménez S. \& López Vélez, G. MGC 46817. Taxon de distribución euroasiática. Rivera \& López Vélez (1987) consideran probable su presencia en Albacete, haciendo referencia a localidades próximas de la Sierra de Segura (Jaén).

\section{BIBLIOGRAFÍA}

MONTSERRAT MARTÍ, M. -1993-Monotropa L. en: Castroviejo et al. (Ed.) Flora Iberica, Vol.IV. C.S.I.C. Madrid.

RIVERA, D. y G. LÓPEZ VÉLEZ - 1987- Orquídeas de la provincia de Albacete. Instituto de Estudios Albacetenses. Albacete.

SÁNCHEZ-GÓMEZ, P., J.F. MOTA POVEDA, F. GÓMEZ MERCADO y F. SÁEZ SOTO -1994Utilización de criterios bioclimáticos y florísticos en la subdivisión biogeográfica del sector subbético (provincia Bética). Acta Bot. Malacitana 19: 185-198.

Aceptado para su publicación en Junio de 1998

Dirección de los autores: Departamento de Biología Vegetal (Botánica), Facultad de Biología, Universidad de Murcia. 30100 Campus de Espinardo (Murcia). 